\title{
A comparison of efficacy of six prediction models for intravenous immunoglobulin resistance in Kawasaki disease
}

\author{
Weiguo Qian ${ }^{\dagger}$, Yunjia Tang ${ }^{\dagger}$, Wenhua Yan, Ling Sun and Haitao Lv ${ }^{*}$
}

\begin{abstract}
Background: Kawasaki disease (KD) is the most common pediatric vasculitis. Several models have been established to predict intravenous immunoglobulin (IVIG) resistance. The present study was aimed to evaluate the efficacy of prediction models using the medical data of KD patients.

Methods: We collected the medical records of patients hospitalized in the Department of Cardiology in Children's Hospital of Soochow University with a diagnosis of KD from Jan 2015 to Dec 2016. IVIG resistance was defined as recrudescent or persistent fever $\geq 36 \mathrm{~h}$ after the end of their IVIG infusion.

Results: Patients with IVIG resistance tended to be younger, have higher occurrence of rash and changes of extremities. They had higher levels of c-reactive protein, aspartate aminotransferase, neutrophils proportion (N\%), total bilirubin and lower level of albumin. Our prediction model had a sensitivity of 0.72 and a specificity of 0.75 . Sensitivity of Kobayashi, Egami, Kawamura, Sano and Formosa were $0.72,0.44,0.48,0.20$, and 0.68 , respectively. Specificity of these models were $0.62,0.82,0.66,0.91$, and 0.48 , respectively.
\end{abstract}

Conclusions: Our prediction model had a powerful predictive value in this area, followed by Kobayashi model while all the other prediction models had less excellent performances than ours.

Keywords: Kawasaki disease, Children, Prediction model, Intravenous immunoglobulin resistance

\section{Background}

Kawasaki disease (KD) is a systemic self-limited vasculitis that mostly occurs in children under 5 years of age. The main complication of the disease is coronary artery abnormality (CAA), which is considered the leading cause of acquired heart disease [1]. Fifty years have passed since the first report of the disease and now $2 \mathrm{~g} / \mathrm{kg}$ intravenous immunoglobulin (IVIG) together with large amount of aspirin is considered the golden primary treatment in the acute stage worldwide. However, approximately $10-20 \%$ patients do not respond to such treatment and presented with prolonged changes in presence of prolonged fever [1]. Moreover, alternative treatments after response failure to initial IVIG treatment are usually unsatisfactory, with a remarkable higher incidence of CAA [2, 3]. Thus, early

\footnotetext{
*Correspondence: haitaoszzz@163.com

${ }^{\dagger}$ Equal contributors

Department of Cardiology, Children's Hospital of Soochow University,

Suzhou, China
}

identification of IVIG resistance is of great importance so that additional therapy in the early stage could be given to reduce the risk of CAA.

In 2006, Kobayashi established a prediction score model of IVIG resistance based on 676 study patients [4]. The related predictors were serum sodium $(\mathrm{Na}) \leq 133 \mathrm{mmol} / \mathrm{L}$, days of illness at initial treatment $\leq 4$, aspartate aminotransferase $(\mathrm{AST}) \geq 100 \mathrm{IU} / \mathrm{L}, \mathrm{N} \% \geq 80 \%$, c-reactive protein $(\mathrm{CRP}) \geq 10 \mathrm{mg} / \mathrm{dL}$, age $\leq 12$ months and platelet count (PLT) $\leq 30 \times 10^{4} / \mathrm{mm}^{3}$. Due to the racial heterogeneity, studies on IVIG resistance prediction score have amassed in recently years in different countries

Previously we have established a prediction model using the KD dataset in this area from 2006 to 2014 [9]. In the present study, we aimed to evaluate the efficacy of these prediction models using the medical data of KD patients hospitalized in Children's Hospital of Soochow University during the last 2 years. 


\section{Methods}

We prospectively collected the medical records of patients hospitalized in the Department of Cardiology in Children's Hospital of Soochow University with a diagnosis of KD from Jan 2015 to Dec 2016. When we evaluated the Kawamura prediction model and parts of the Formosa model, the medical records were retrospectively collected. Children's Hospital of Soochow University is a tertiary hospital that serves most children of this area and some of the children from surrounding cities. Kawasaki disease was confirmed when patients had fever for more than 5 days plus four of the following five characteristics. 1. Rash. 2. Bilateral conjunctive injection. 3. Cervical lymphadenopathy. 4. Changes of the extremities. 5. Oral mucosal changes. Incomplete KD was defined as patients with $\geq 5$ days of fever and < 4 classic criteria, but who had CAA upon echocardiography or a set of suspect laboratory criteria according to the AHA guideline [10]. IVIG resistance was referred to when a patient developed recrudescent or persistent fever $\geq 36 \mathrm{~h}$ after the end of their IVIG infusion [10]. All febrile patients received $2 \mathrm{~g} / \mathrm{kg}$ IVIG and $30-50 \mathrm{mg} / \mathrm{kg}$ aspirin as the guideline recommended [10]. The dosage of aspirin was decreased to $3-5 \mathrm{mg} / \mathrm{kg} /$ day until the patients were afebrile for 3-4 days. All parents of the patients gave their informed consent. The study was approved by the Ethics Committee of Children's Hospital of Soochow University (No: 2014LW003).

Demographic and clinical characteristics were obtained on admission. Laboratory data regarding CRP, PLT, Na, $\mathrm{N} \%$, serum albumin (ALB), alanine aminotransferase (ALT), AST, total bilirubin (TB), neutrophils count, lymphocytes count were obtained within $24 \mathrm{~h}$ on admission. In our prediction score model, two points were assigned to age younger than 6 months and ALB lower than $35 \mathrm{~g} /$ L. One point was assigned to $\mathrm{N} \% \geq 80 \%$, presence of rash and edema of extremities. Our model had a sensitivity of $71.4 \%$ and a specificity of $76.0 \%$. Detailed information of the prediction models are shown in Table 1.

Table 1 Prediction score models of IVIG resistance in KD patients

\begin{tabular}{|c|c|c|c|c|c|c|c|c|c|}
\hline $\begin{array}{l}\text { Prediction } \\
\text { models }\end{array}$ & Nation & Year & $\begin{array}{l}\text { Enrolled } \\
\text { patients, n }\end{array}$ & $\begin{array}{l}\text { Patients with IVIG } \\
\text { resistance, } n\end{array}$ & Sensitivity, \% & Specificity, \% & Risk factors & Points & $\begin{array}{l}\text { Predicted risk } \\
\text { (score) }\end{array}$ \\
\hline \multirow[t]{7}{*}{ Kobayashi } & \multirow[t]{7}{*}{ Japan } & \multirow[t]{7}{*}{2006} & \multirow[t]{7}{*}{528} & \multirow[t]{7}{*}{148} & \multirow[t]{7}{*}{86} & \multirow[t]{7}{*}{68} & Age $\leq 12 \mathrm{mo}$ & 1 & \multirow{7}{*}{$\begin{array}{l}\text { Low risk (0-2) } \\
\text { High risk }(\geq 3)\end{array}$} \\
\hline & & & & & & & Illness days $\leq 4 \mathrm{~d}$ & 2 & \\
\hline & & & & & & & $\mathrm{CRP} \geq 10 \mathrm{mg} / \mathrm{dL}$ & 1 & \\
\hline & & & & & & & $\mathrm{AST} \geq 100 \mathrm{IU} / \mathrm{L}$ & 2 & \\
\hline & & & & & & & $\mathrm{PLT} \leq 300 \times 10^{9} / \mathrm{L}$ & 1 & \\
\hline & & & & & & & $\mathrm{Na} \leq 133 \mathrm{mmol} / \mathrm{L}$ & 2 & \\
\hline & & & & & & & $\mathrm{N} \% \geq 80 \%$ & 2 & \\
\hline \multirow[t]{5}{*}{ Egami } & \multirow[t]{5}{*}{ Japan } & \multirow[t]{5}{*}{2006} & \multirow[t]{5}{*}{320} & \multirow[t]{5}{*}{41} & \multirow[t]{5}{*}{78} & \multirow[t]{5}{*}{76} & Age $\leq 6 \mathrm{mo}$ & 1 & \multirow{5}{*}{$\begin{array}{l}\text { Low risk (0-2) } \\
\text { High risk }(\geq 3)\end{array}$} \\
\hline & & & & & & & Illness days $\leq 4 \mathrm{~d}$ & 1 & \\
\hline & & & & & & & $\mathrm{CRP} \geq 8 \mathrm{mg} / \mathrm{dl}$ & 1 & \\
\hline & & & & & & & $\mathrm{ALT} \geq 80 \mathrm{IU} / \mathrm{L}$ & 2 & \\
\hline & & & & & & & $\mathrm{PLT}<300 \times 10^{9} / \mathrm{L}$ & 1 & \\
\hline Kawamura & Japan & 2016 & 405 & 85 & 71 & 69 & $\begin{array}{l}N L R \geq 3.83 \\
P L R \geq 150\end{array}$ & $\begin{array}{l}- \\
-\end{array}$ & - \\
\hline \multirow[t]{3}{*}{ Sano } & \multirow[t]{3}{*}{ Japan } & \multirow[t]{3}{*}{2007} & \multirow[t]{3}{*}{112} & \multirow[t]{3}{*}{22} & \multirow[t]{3}{*}{77} & \multirow[t]{3}{*}{86} & $\mathrm{CRP} \geq 7.0 \mathrm{mg}$ & 1 & \multirow{3}{*}{$\begin{array}{l}\text { Low risk }(0-1) \\
\text { High risk }(\geq 2)\end{array}$} \\
\hline & & & & & & & $\mathrm{TB} \geq 0.9 \mathrm{mg} / \mathrm{dl}$ & 1 & \\
\hline & & & & & & & AST $\geq 200 \mathrm{IU} / \mathrm{L}$ & 1 & \\
\hline \multirow[t]{3}{*}{ Formosa } & \multirow[t]{3}{*}{ Taiwan } & \multirow[t]{3}{*}{2015} & \multirow[t]{3}{*}{248} & \multirow[t]{3}{*}{29} & \multirow[t]{3}{*}{86.2} & \multirow[t]{3}{*}{81.3} & lymphadenopathy & 1 & Low risk (0-2) \\
\hline & & & & & & & $\mathrm{N} \% \geq 60 \%$ & 2 & High risk $(\geq 3)$ \\
\hline & & & & & & & $A L B<35 \mathrm{~g} / \mathrm{L}$ & 1 & \\
\hline \multirow[t]{5}{*}{ Ours } & China & 2016 & 910 & 46 & 71.4 & 76.0 & Age $<6$ months & 2 & Low risk (0-2) \\
\hline & & & & & & & Rash & 1 & HIgh risk $(\geq 3)$ \\
\hline & & & & & & & Edema of extremities & 1 & \\
\hline & & & & & & & N\% $\geq 80 \%$ & 1 & \\
\hline & & & & & & & $A L B<35 \mathrm{~g} / \mathrm{L}$ & 2 & \\
\hline
\end{tabular}




\section{Statistical analysis}

All analyses were carried out by means of a SPSS statistical software package, version 22.0 (IBM, Armonk, NY, USA). Data are expressed as mean \pm standard deviation (SD), median with quartiles or number with percentage as appropriate. Descriptive statistics were performed on the demographic characteristics. Parametric and nonparametric comparative tests for continuous data and $x^{2}$ test for categorical data were used to compare variables between groups. Sensitivity, specificity, positive predictive value (PPV) and negative predictive value (NPV) were used to determine the efficacy of the prediction models. Area under the receiver operating characteristic (ROC) curve was calculated to evaluate capacity of each model. A $P<0.05$ was considered statistically significant.

\section{Results}

A total of 505 patients were diagnosed with $\mathrm{KD}$ during the study period. One patient failed to be treated with IVIG for her parents' refusal. As a result, 504 patients were enrolled in the present study. 318 were males and 186 were females, yielding a male-to-female ratio of
1.71:1. 153 (30.3\%) patients were under one year old and 467 (92.7\%) were under five years old. The median age were $20(11,36)$ months. $322(63.9 \%)$ patients were complete KD while the remaining $182(36.1 \%)$ were incomplete cases. 25 (5.0\%) patients were identified as IVIG resistance. The characteristics of the patients are shown in Table 2. Significant differences were demonstrated in age $<6$ months, presence of rash and edema of extremities. For laboratory findings, patients with IVIG resistance had higher levels of CRP, AST, N\% and TB. On the other hand, they tended to have lower level of ALB.

The scores of the prediction models were calculated for each patient, and then the patients were assigned to the high or low risk group. Table 3 shows the number of patients in the high and low-risk categories, together with the relative sensitivity, specificity, NPV, PPV and area of ROC curve of each model. Our prediction model had a sensitivity of 0.72 and a specificity of 0.75 . Sensitivity of Kobayashi, Egami, Kawamura, Sano and Formosa were $0.72,0.44,0.48,0.20$, and 0.68 , respectively. Specificity of these models were $0.62,0.82,0.66,0.91$, and 0.48 , respectively.

Table 2 Demographic, clinical and laboratory characteristics between intravenous immunoglobulin (IVIG) resistant and IVIG responsive KD patients

\begin{tabular}{|c|c|c|c|c|}
\hline Variables & Total $(n=504)$ & IVIG resistant patients $(n=479)$ & IVIG responsive patients $(n=25)$ & $P$ value \\
\hline Male, $n(\%)$ & $318(63.1)$ & $303(60.1)$ & $15(3.0)$ & 0.726 \\
\hline Age in months, median (quartile) & $20(11,36)$ & $20(11,35)$ & $15(5.5,42.5)$ & 0.456 \\
\hline$<1$ yr., $n(\%)$ & $153(30.4)$ & $142(28.2)$ & $11(2.2)$ & 0.128 \\
\hline$<6$ months, $n(\%)$ & $58(11.5)$ & $51(10.1)$ & $7(1.4)$ & 0.008 \\
\hline Oral mucosal changes, $n(\%)$ & $457(90.7)$ & $435(86.3)$ & $22(4.4)$ & $0.720^{*}$ \\
\hline Strawberry tongue, $n$ (\%) & $384(76.2)$ & $367(72.8)$ & $16(3.2)$ & 0.150 \\
\hline Rash, $n(\%)$ & $394(78.2)$ & $370(73.4)$ & $24(4.8)$ & 0.027 \\
\hline Edema of extremities, $n$ (\%) & $224(44.4)$ & $204(40.5)$ & $20(4.0)$ & $<0.001$ \\
\hline Desquamation of the fingertips, $n(\%)$ & $268(53.2)$ & $252(50.0)$ & $16(3.2)$ & 0.266 \\
\hline Cervical lymphadenopathy, n (\%) & $398(79.0)$ & $380(79.4)$ & $18(3.6)$ & 0.381 \\
\hline $\begin{array}{l}\text { Days of illness at initial treatment, mean } \pm S D \\
\text { (median), days }\end{array}$ & $6.8 \pm 2.0(6.0)$ & $6.8 \pm 2.0(6.0)$ & $6.2 \pm 2.0(6.0)$ & 0.156 \\
\hline CRP, median (quartile), mg/dl & $69.1(37.6,112.7)$ & $65.6(36.3,111.4)$ & $94.4(84.2,134.9)$ & 0.001 \\
\hline ALT, median (quartile), IU/L & $22.7(13.4,55.7)$ & $22.2(13.2,54.1)$ & $29.5(17.8,104.5)$ & 0.051 \\
\hline AST, median (quartile), IU/L & $31.0(24.3,43.8)$ & $31.0(24.1,43.0)$ & $42.6(28.5,53.6)$ & 0.034 \\
\hline $\mathrm{Na}$, mean $\pm \mathrm{SD}$ (median), $\mathrm{mmol} / \mathrm{L}$ & $135(133,137)$ & $135(133,137)$ & $133(131,137)$ & 0.247 \\
\hline ALB, mean $\pm S D$ (median), g/L & $38.6(35.8,40.7)$ & $38.8(35.8,40.8)$ & $36.3(32.8,38.8)$ & 0.005 \\
\hline $\mathrm{PLT}$, mean $\pm \mathrm{SD}\left(\right.$ median),$\times 10^{9} / \mathrm{L}$ & $357(284,453)$ & $357(287,454)$ & $365(224,400)$ & 0.169 \\
\hline N\%, mean \pm SD (median) & $65.3(53.3,75.2)$ & $64.9(53.4,74.6)$ & $76.8(55.9,89.1)$ & 0.026 \\
\hline NLR, mean $\pm S D$ (median) & $2.4(1.4,4.1)$ & $2.4(1.4,4.1)$ & $3.5(1.1,11.7)$ & 0.198 \\
\hline $\mathrm{PLR}$, mean \pm SD (median) & $100.8(69.2,145.1)$ & $100.4(68.9,144.1)$ & $118.7(71.0,218.8)$ & 0.158 \\
\hline $\mathrm{TB}$, mean $\pm \mathrm{SD}$ (median), $\mathrm{mmol} / \mathrm{L}$ & $5.1(3.5,7.7)$ & $5.0(3.5,7.5)$ & $7.9(5.0,11.2)$ & 0.002 \\
\hline
\end{tabular}

SD standard deviation, CRP c-reactive protein, PLT platelet count, Na serum sodium, N\% percentage of neutrophils, $A L B$ serum albumin, $A L T$ alanine aminotransferase, AST aspartate aminotransferase, TB total bilirubin, NLR neutrophil-to-lymphocyte ratio, $P L R$ platelet-to-lymphocyte ratio

*Fisher's exact test was used 
Table 3 Prediction score models in patients with IVIG resistance

\begin{tabular}{|c|c|c|c|c|c|c|c|c|c|}
\hline \multirow{2}{*}{$\begin{array}{l}\text { Prediction } \\
\text { models }\end{array}$} & \multirow[t]{2}{*}{ Category } & \multicolumn{2}{|c|}{ Response to IVIG } & \multirow[t]{2}{*}{ Sensitivity } & \multirow[t]{2}{*}{ Specificity } & \multirow[t]{2}{*}{ PPV } & \multirow[t]{2}{*}{ NPV } & \multirow{2}{*}{$\begin{array}{l}\text { Area under } \\
\text { the ROC curve }\end{array}$} & \multirow[t]{2}{*}{$95 \% \mathrm{Cl}$} \\
\hline & & Resistant & Responsive & & & & & & \\
\hline \multirow[t]{2}{*}{ Kobayashi } & High risk & 18 & 184 & 0.72 & 0.62 & 0.09 & 0.98 & 0.74 & $0.65-0.84$ \\
\hline & Low risk & 7 & 295 & & & & & & \\
\hline \multirow[t]{2}{*}{ Egami } & High risk & 11 & 88 & 0.44 & 0.82 & 0.11 & 0.97 & 0.70 & $0.59-0.81$ \\
\hline & Low risk & 14 & 391 & & & & & & \\
\hline \multirow[t]{2}{*}{ Kawamura ${ }^{a}$} & High risk & 10 & 140 & 0.48 & 0.66 & 0.07 & 0.96 & 0.58 & $0.45-0.71$ \\
\hline & Low risk & 11 & 267 & & & & & & \\
\hline \multirow[t]{2}{*}{ Sano } & High risk & 5 & 43 & 0.20 & 0.91 & 0.10 & 0.96 & 0.58 & $0.46-0.70$ \\
\hline & Low risk & 20 & 436 & & & & & & \\
\hline \multirow[t]{2}{*}{ Formosa } & High risk & 17 & 248 & 0.68 & 0.48 & 0.06 & 0.97 & 0.58 & $0.48-0.68$ \\
\hline & Low risk & 8 & 231 & & & & & & \\
\hline \multirow[t]{2}{*}{ Ours } & High risk & 18 & 120 & 0.72 & 0.75 & 0.13 & 0.98 & 0.80 & $0.72-0.88$ \\
\hline & Low risk & 7 & 359 & & & & & & \\
\hline
\end{tabular}

PPV Positive predictive value, NPV Negative predictive value, $R O C$ receiver operating characteristic, $C l$ confidence interval

${ }^{a} 76$ patients were excluded for incomplete data when we calculated the Kawamura prediction model scores

\section{Discussion}

In the present study, we evaluated the efficacy of the Kobayashi, Egami, Kawamura, Sano, Formosa, as well as our own prediction model using the medical data of KD in the past 2 years. We found Kobayashi and our prediction model had a relatively high sensitivity of $72 \%$ while our model had a higher specificity than Kobayashi. Sensitivity of Egami, Kawamura and Sano were all lower than $50 \%$. Sensitivity of Formosa was intermediate with the lowest specificity. Our data suggested that our prediction model had a powerful predictive value in this area, followed by Kobayashi model while all the other prediction models had less excellent performances than ours. Actually, these findings might provide evidences for our future work on additional initial treatment in KD patients.

Kobayashi, Egami and Sano prediction models were mainly based on age, illness day and laboratory variables. The related predictive risk factors such as higher levels of CRP and N\%, lower level of ALB were later proved to be effective predictors in different areas in our country $[9,11,12]$. However, the node and the point score in each prediction model were different due to a regional difference.

Developed in 2015, Formosa model was based on KDassociated manifestations besides laboratory characteristics. They developed the model in 181 patients and further validated the data in another 67 patients. The validation results showed the sensitivity and specificity of the prediction model were $71.4 \%$ and $81.0 \%$, which was slightly lower compared with those in the development dataset [7]. Although two of the three predictors (N\% and ALB) were also included in our prediction model, Formosa model didn't have excellent performance in the present study. Our results were in consistence with Song's study [13]. The assignment of 2 points to N\% $\geq 60 \%$ in the Formosa model might increase the number of high-risk patients identified by that model.

Kawamura prediction model was also developed in Japan based on a single-center data. However, the prediction model was developed in 2016. That was to say, the prediction model was not fully established when we started the present study and thus we retrospectively reviewed the data according to the model at the end of our study. The prediction model was proved to have a sensitivity of $71 \%$ and a specificity of $69 \%$ in the combination of both neutrophil-to-lymphocyte ratio (NLR) $\geq 3.83$ and platelet-to-lymphocyte ratio (PLR) $\geq 150$ [8]. In another study including $437 \mathrm{KD}$ patients which was carried out in the same medical center, the authors found the sensitivity and specificity of the prediction model were similar to Kobayashi model [14]. However, NLR and PLR could be calculated quickly and easily with the blood routine test alone. Neutrophils are the most abundant inflammatory cells, which may partly reflect the severity of the inflammation. In KD mouse models, influx of neutrophils and macrophages occurred 1 day after the stimulus, followed by a second neutrophil infiltration 28 days later, which persisted for several weeks [15]. In autopsied KD patients, neutrophils predominated in the earlier stage of the disease when macrophages predominated in the later stage [16]. The specific mechanisms remained obscure and were possibly related to the decreased apoptosis of neutrophils $[17,18]$. Due to the activation of macrophages, elevated level of platelet was observed in most patients in the convalescent stage. On the other hand, lymphocytes also played a pivotal role in inflammatory processes and lymphocytopenia was associated with more severe 
inflammation owing to increased apoptosis [19, 20]. Although combination of NLR $\geq 3.83$ and PLR $\geq 150$ was more effective than either the NLR or PLR alone, an NLR of $\geq 3.83$ or a PLR of $\geq 150$ was an independent predictor of IVIG resistance [8]. Thus, patients with more than one predictor were assigned to high risk group and the remaining were assigned to low risk group. Unfortunately, the easily calculated prediction model had less powerful predictive efficacy. Factors such as different treatment regimens and methodology might be associated with the divergence.

It was not surprising that our prediction model had a higher efficacy in predicting IVIG resistance. We previously compared the clinical and laboratory characteristics of the patients with different IVIG responses. The sensitivity and specificity were $71.4 \%$ and $76.0 \%$ in the development dataset, respectively, which were similar to the results in the present study [9]. The divergences of sensitivity and specificity among these models and ours might be explained by different genetic backgrounds [1], definition of IVIG resistance and meteorological factors [21].

Though the incidences of IVIG resistance varied all of the world, mostly were between $10 \%$ and 20\% [22-24]. It was quite low in the present study, which was similar to the incidence of Shanghai in the latest survey [25]. We previously had found that $5.1 \%$ of all patients were IVIG resistant during the past 9 years [9], which was almost the same as the present study. We speculated the time of initial IVIG treatment, racial differences and lots of IVIG might attribute to the discrepancy in the incidences. Unfortunately, all of these six prediction models had a relatively low PPV. Our results were coincident with previous study [13], which could be explained by a low IVIG resistance incidence (5\% in the present study).

All the prediction models described in the present study were developed in Asia populations, most of which were from Japan. However, all had shown moderate sensitivity. What was more, previous study had found a lower sensitivity in an American population [26]. Due to an unknown origin of $\mathrm{KD}$, we speculated a prediction model combined clinical, laboratory characteristics, with biomarkers or other specific indicators might have a better performance.

It should be noted that a total of 505 patients were diagnosed with KD in 2015 and 2016, which were almost half of those diagnosed between 2006 and 2014 [9]. In 2014, the Chinese government introduced the second child policy, leading to a dramatic increase in the number of children aged under 2 years in recent years. Thus, it was not surprising that the number of KD patients were increasing rapidly.

This study had some limitations. First, part of the study was retrospective and the missing data might lead to selection bias. Second, we did not conduct stringent validation by using an independent $\mathrm{KD}$ cohort from other institutions in this area, although most KD patients were diagnosed and treated in our hospital. Third, we didn't evaluate the efficacy of other models such as Tremoulet prediction model for the inconvenience to get such variables. Further large-scaled studies were warranted to further verify the efficacy of the prediction models and moreover, to develop a more efficient prediction model suited for this area.

\section{Conclusion}

Our prediction model had a powerful predictive value in this area, followed by Kobayashi model while all the other prediction models had less excellent performances than ours. The prediction model could help identify IVIG resistance in clinical work.

\section{Abbreviations}

ALB: Serum albumin; ALT: Alanine aminotransferase; AST: Aspartate aminotransferase; CAA: Coronary artery abnormality; CRP: C-reaction protein; IVIG: Intravenous immunoglobulin; KD: Kawasaki disease; N\%: Neutrophils proportion; Na: serum sodium; NLR: Neutrophil-to-lymphocyte ratio; NPV: Negative predictive value; PLR: Platelet-to-lymphocyte ratio; PLT: Platelet; PPV: Positive predictive value; ROC: Receiver operating characteristic; TB: Total bilirubin; WBC: White blood cell

\section{Acknowledgements}

Not applicable.

\section{Funding}

This study was financially supported by the National Natural Science Foundation of China (No. 81570455, 81700439), Jiangsu Province Science Foundation (BE2017660), the talent foundation of Jiangsu Province (No. WSN-070 and ZDRCA2016049), and Technology Projects for the Youth of Suzhou (KJXW2016021)

Availability of data and materials

The datasets used and/or analyzed during the current study are available from the corresponding author on reasonable request.

Authors' contributions

YJT and WGQ analyzed data and wrote the manuscript. HTL designed the study and revised the manuscript. WHY and LS collected and analyzed data. All authors reviewed and approved the manuscript.

Ethics approval and consent to participate

All parents of the patients gave their informed consent. The study was approved by the Ethics Committee of Children's Hospital of Soochow University (No: 2014LW003).

Consent for publication Not applicable.

Competing interests

The authors declare that they have no competing interests.

\section{Publisher's Note}

Springer Nature remains neutral with regard to jurisdictional claims in published maps and institutional affiliations. 
Received: 4 January 2018 Accepted: 25 February 2018

Published online: 09 March 2018

\section{References}

1. BW M, AH R, JW N, JC B, AF B, M G, AL B, MA J, M T, PB S. Diagnosis, Treatment, and Long-Term Management of Kawasaki Disease: A Scientific Statement for Health Professionals From the American Heart Association. Circulation. 2017;135(17):e927-99.

2. Sano T, Kurotobi S, Matsuzaki K, Yamamoto T, Maki I, Miki K, Kogaki S, Hara J. Prediction of non-responsiveness to standard high-dose gamma-globulin therapy in patients with acute Kawasaki disease before starting initial treatment. Eur J Pediatr. 2007;166(2):131-7.

3. Teraguchi M, Ogino H, Yoshimura K, Taniuchi S, Kino M, Okazaki H, Kaneko K. Steroid pulse therapy for children with intravenous immunoglobulin therapy-resistant Kawasaki disease: a prospective study. Pediatr Cardiol. 2013;34(4):959-63. https://doi.org/10.1007/s00246-012-0589-9.

4. Kobayashi T, Inoue Y, Takeuchi K, Okada Y, Tamura K, Tomomasa T, Kobayashi T, Morikawa A. Prediction of intravenous immunoglobulin unresponsiveness in patients with Kawasaki disease. Circulation. 2006;113(22):2606-12.

5. Egami K, Muta H, Ishii M, Suda K, Sugahara Y, lemura M, Matsuishi T. Prediction of resistance to intravenous immunoglobulin treatment in patients with Kawasaki disease. Pediatrics. 2006;149(2):237-40.

6. Tremoulet AH, Best BM, Song S, Wang S, Corinaldesi E, Eichenfield JR, Martin DD, Newburger JW, Burns JC. Resistance to intravenous immunoglobulin in children with Kawasaki disease. J Pediatr. 2008;153(1):117-21.

7. Lin MT, Chang CH, Sun LC, Liu HM, Chang HW, Chen CA, Chiu SN, Lu CW, Chang LY, Wang JK, Wu MH. Risk factors and derived Formosa score for intravenous immunoglobulin unresponsiveness in Taiwanese children with Kawasaki disease. J Formos Med Assoc. 2016;115(5):350-5. https://doi.org/10.1016/j.fma.2015.03.012

8. Kawamura Y, Takeshita S, Kanai T, Yoshida Y, Nonoyama S. The combined usefulness of the neutrophil-to-lymphocyte and platelet-to-lymphocyte ratios in predicting intravenous immunoglobulin resistance with Kawasaki disease. J Pediatr. 2016;178:281-4. https://doi.org/10.1016/j.jpeds.2016.07.035.

9. Tang Y, Yan W, Sun L, Huang J, Qian W, Ding Y, Lv H. Prediction of intravenous immunoglobulin resistance in Kawasaki disease in an East China population. Clin Rheumatol. 2016;35(11):2771-6. https://doi.org/10.1007/ s10067-016-3370-2.

10. Newburger JW, Takahashi M, Gerber MA, Gewitz MH, Tani LY, Burns JC, Shulman ST, Bolger AF, Ferrieri P, Baltimore RS, Wilson WR, Baddour LM, Levison ME, Pallasch TJ, Falace DA, Taubert KA, Committee on Rheumatic Fever E, Kawasaki D, Council on Cardiovascular Disease in the $Y$, American Heart A, American Academy of $P$. Diagnosis, treatment, and long-term management of Kawasaki disease: a statement for health professionals from the committee on rheumatic fever, endocarditis and Kawasaki disease, council on cardiovascular disease in the young, American Heart Association. Circulation. 2004;110(17):2747-71. https://doi.org/10.1161/01.CIR.0000145143.19711.78.

11. Fu PP, Du ZD, Pan YS. Novel predictors of intravenous immunoglobulin resistance in Chinese children with Kawasaki disease. Pediatr Infect Dis J. 2013:32(8):319-23.

12. Xie T, Wang Y, Fu S, Wang W, Xie C, Zhang Y, Gong F. Predictors for intravenous immunoglobulin resistance and coronary artery lesions in Kawasaki disease. Pediatr Rheumatol Online J. 2017;15(1):17. https://doi.org/ 10.1186/s12969-017-0149-1

13. Song R, Yao W, Li X. Efficacy of four scoring Systems in Predicting Intravenous Immunoglobulin Resistance in children with Kawasaki disease in a Children's Hospital in Beijing, North China. J Pediatr. 2017;184:120-4. https://doi.org/10.1016/j.jpeds.2016.12.018.

14. Takeshita S, Kanai T, Kawamura Y, Yoshida Y, Nonoyama S. A comparison of the predictive validity of the combination of the neutrophil-to-lymphocyte ratio and platelet-to-lymphocyte ratio and other risk scoring systems for intravenous immunoglobulin (ivig)-resistance in Kawasaki disease. PLoS One 2017;12(5):e0176957. https://doi.org/10.1371/journal.pone.0176957.

15. Stock AT, Hansen JA, Sleeman MA, McKenzie BS, Wicks IP. GM-CSF primes cardiac inflammation in a mouse model of Kawasaki disease. J Exp Med. 2016:213(10):1983-98. https://doi.org/10.1084/jem.20151853.

16. Harada M, Yokouchi Y, Oharaseki T, Matsui K, Tobayama H, Tanaka N, Akimoto K, Takahashi K, Kishiro M, Shimizu T, Takahashi K. Histopathological characteristics of myocarditis in acute-phase Kawasaki disease. Histopathology. 2012;61(6):1156-67. https://doi.org/10.1111/j. 1365-2559.2012.04332.x
17. Tsujimoto H, Takeshita S, Nakatani K, Kawamura Y, Tokutomi T, Sekine I. Delayed apoptosis of circulating neutrophils in Kawasaki disease. Clin Exp Immunol. 2001;126(2):355-64.

18. Tsujimoto H, Takeshita S, Nakatani K, Kawamura Y, Tokutomi T, Sekine I. Intravenous immunoglobulin therapy induces neutrophil apoptosis in Kawasaki disease. Clin Immunol. 2002;103(2):161-8. https://doi.org/10.1006/ clim.2002.5209.

19. Chung KP, Chang HT, Lo SC, Chang LY, Lin SY, Cheng A, Huang YT, Chen CC, Lee MR, Chen YJ, Hou HH, Hsu CL, Jerng JS, Ho CC, Huang MT, Yu CJ, Yang PC. Severe lymphopenia is associated with elevated plasma interleukin-15 levels and increased mortality during severe sepsis. Shock. 2015;43(6):569-75. https://doi.org/10.1097/SHK.0000000000000347.

20. Hotchkiss RS, Osmon SB, Chang KC, Wagner TH, Coopersmith CM, Karl IE. Accelerated lymphocyte death in sepsis occurs by both the death receptor and mitochondrial pathways. J Immunol. 2005;174(8):5110-8.

21. Jung CR, Chen WT, Lin YT, Hwang BF. Ambient air pollutant exposures and hospitalization for Kawasaki disease in Taiwan: a case-crossover study (2000-2010). Environ Health Perspect. 2017;125(4):670-6. https://doi.org/10.1289/EHP137.

22. Kim GB, Park S, Eun LY, Han JW, Lee SY, Yoon KL, Yu JJ, Choi JW, Lee KY Epidemiology and clinical features of Kawasaki disease in South Korea, 2012-2014. 2017;36(5):482-5.

23. Makino N, Nakamura Y, Yashiro M, Ae R, Tsuboi S, Aoyama Y, Kojo T, Uehara R, Kotani K, Yanagawa H. Descriptive epidemiology of Kawasaki disease in Japan, 2011-2012: from the results of the 22nd nationwide survey. J Epidemiol. 2015; 25(3):239-45. https://doi.org/10.2188/jea.JE20140089.

24. Saundankar J, Yim D, Itotoh B, Payne R, Maslin K, Jape G, Ramsay J, Kothari D, Cheng A, Burgner D. The epidemiology and clinical features of Kawasaki disease in Australia. Pediatrics. 2014;133(4):1009-14.

25. Chen JJ, Ma XJ, Liu F, Yan WL, Huang MR, Huang M, Huang GY, Shanghai Kawasaki Disease Research G. Epidemiologic features of Kawasaki disease in shanghai from 2008 through 2012. Pediatr Infect Dis J. 2016;35(1):7-12. https://doi.org/10.1097/INF.0000000000000914

26. Sleeper LA, Minich LA, Mccrindle BM, Li JS, Mason W, Colan SD, Atz AM, Printz BF, Baker A, Vetter VL. Evaluation of Kawasaki disease risk-scoring Systems for Intravenous Immunoglobulin Resistance. J Pediatr. 2011;158(5):831-5.

\section{Submit your next manuscript to BioMed Central and we will help you at every step:}

- We accept pre-submission inquiries

- Our selector tool helps you to find the most relevant journal

- We provide round the clock customer support

- Convenient online submission

- Thorough peer review

- Inclusion in PubMed and all major indexing services

- Maximum visibility for your research

Submit your manuscript at www.biomedcentral.com/submit
C) BioMed Central 